\title{
DESENVOLVIMENTO DE MANIPULADOR ROBÓTICO CARTESIANO DE BAIXO CUSTO PARA MOVIMENTAÇÃO DE PRODUTOS EM LINHAS DE PRODUÇÃO INDUSTRIAIS*
}

\author{
Jeferson Preti ${ }^{1}$ \\ Cristiano Bertulucci Silveira ${ }^{1}$ \\ Flávio Alessandro Serrão Gonçalves²
}

\section{Resumo}

Este trabalho apresenta a análise, o projeto e o desenvolvimento de um manipulador robótico industrial de baixo custo para linhas de produção. $O$ aparato proposto possui potencial para contribuir na melhoria das condições de utilização de células robóticas no cenário industrial nacional, auxiliando na superação dos desafios existentes na implantação de células robóticas por pequenas e médias empresas, nomeadamente, custos de implantação, manutenção e reprogramação/reconfiguração. O manipulador robótico industrial foi projetado considerando uma estrutura metálica leve de baixo custo, com elementos mecânicos de precisão média e não dedicados, facilmente encontrados no mercado nacional. Além disso, o manipulador robótico foi projetado para ser capaz de alcançar velocidades médias provendo tempos de ciclo de operação quase equivalentes aos apresentados por robôs polares articulados convencionais, nas mesmas aplicações. O sistema de controle foi concebido para não empregar o dispendioso sistema convencional de hardware centralizado de controle de eixos, sendo esta operação realizada por algoritmo computacional executado no mesmo PC responsável pela gestão e integração dos processos. Assim, a operação emprega dispositivos acionadores descentralizados considerando o envio dos sinais de referência diretamente aos acionadores, possibilitando a compensação das restrições dos esforços da estrutura com recursos de suavização de trajetórias. A integração com o usuário foi projetada para possuir uma interface gráfica de manipulação amigável e que permita facilmente os processos de operação, manutenção e de reconfiguração. Fornecendo ainda, recursos de supervisão, histórico de falhas e assistência remota. Por fim, um protótipo do manipulador robótico industrial proposto é apresentado demonstrando as principais características construtivas e operacionais.

Palavras-chave: Manipulador robótico industrial; Robô cartesiano.

\section{DEVELOPMENT OF LOW COST ROBOTIC CARTESIAN MANIPULATOR TO DRIVE PRODUCTS IN INDUSTRIAL PRODUCTION LINES}

\begin{abstract}
This work presents the analysis, design and development of a low cost industrial robot manipulator for production lines. The proposed apparatus has the potential to contribute improving the use of robotic cells in the national industrial scene, helping to overcome the existing challenges in deployment of robotic cells by small and medium enterprises, in particular, implementation costs, maintenance and reprogramming /reconfiguration. Industrial robot manipulator was designed considering a low cost light steel structure, with average precision non-dedicated mechanical elements, easily found on the national market. In addition, the robotic manipulator was designed to be able to achieve average speeds with times of operation almost equivalent to those presented by conventional polar articulated robots in the same applications. The control system was designed without the costly centralized hardware system of axes control, this operation being performed by computer algorithm running on the same PC responsible for the management and integration of processes. Thus, the operation employs decentralized devices providing the reference signals directly to the actuators, allowing the mitigation of the efforts restrictions in structure with programmable smoothing of trajectories. Integration with the user is designed to have a user-friendly graphical interface allowing an easy handling of operation processes, maintenance and reconfiguration. Furthermore, it can provide resources for supervision, fault history and remote assistance. Finally, a prototype of the proposed industrial robot manipulator is presented in order to corroborate the construction and operational characteristics.
\end{abstract}

Keywords: Industrial robotic manipulator, Cartesian robot.

1 Eng. Elétrico, Mestrando, Pós Graduação em Engenharia Elétrica, Faculdade de Engenharia de Bauru (FEB), Unesp, Bauru, SP, Brasil.

2 Pós-Doutorado em Engenharia Elétrica, Professor Assistente Doutor da Faculdade de Automação e Controle, Campus Experimental de Sorocaba, Unesp, Sorocaba, SP, Brasil.

* Contribuição técnica ao $18^{\circ}$ Seminário de Automação e TI Industrial, 23 a 26 de setembro de 2014, São

Paulo, SP, Brasil. 


\section{INTRODUÇÃO}

A indústria brasileira no decorrer de sua história alternou momentos de baixo crescimento com ápices de desenvolvimento, como o ocorrido na década de 60 através da abertura da economia para o capital internacional que propiciou a vinda de grandes empresas multinacionais, principalmente do setor automobilístico. [1] Atingindo situação de apogeu na década de 80 quando o setor industrial chegou a responder por mais de um quarto do produto interno bruto do país PIB $(27,2 \%)$, e de retomada de crescimento na década de 2000 , chegando a 19,2\% do PIB em 2004, conforme mostra a Figura 1. A indústria brasileira vem crescendo, mas com taxa de crescimento inferior que a dos demais setores, perdendo a participação no PIB [2].

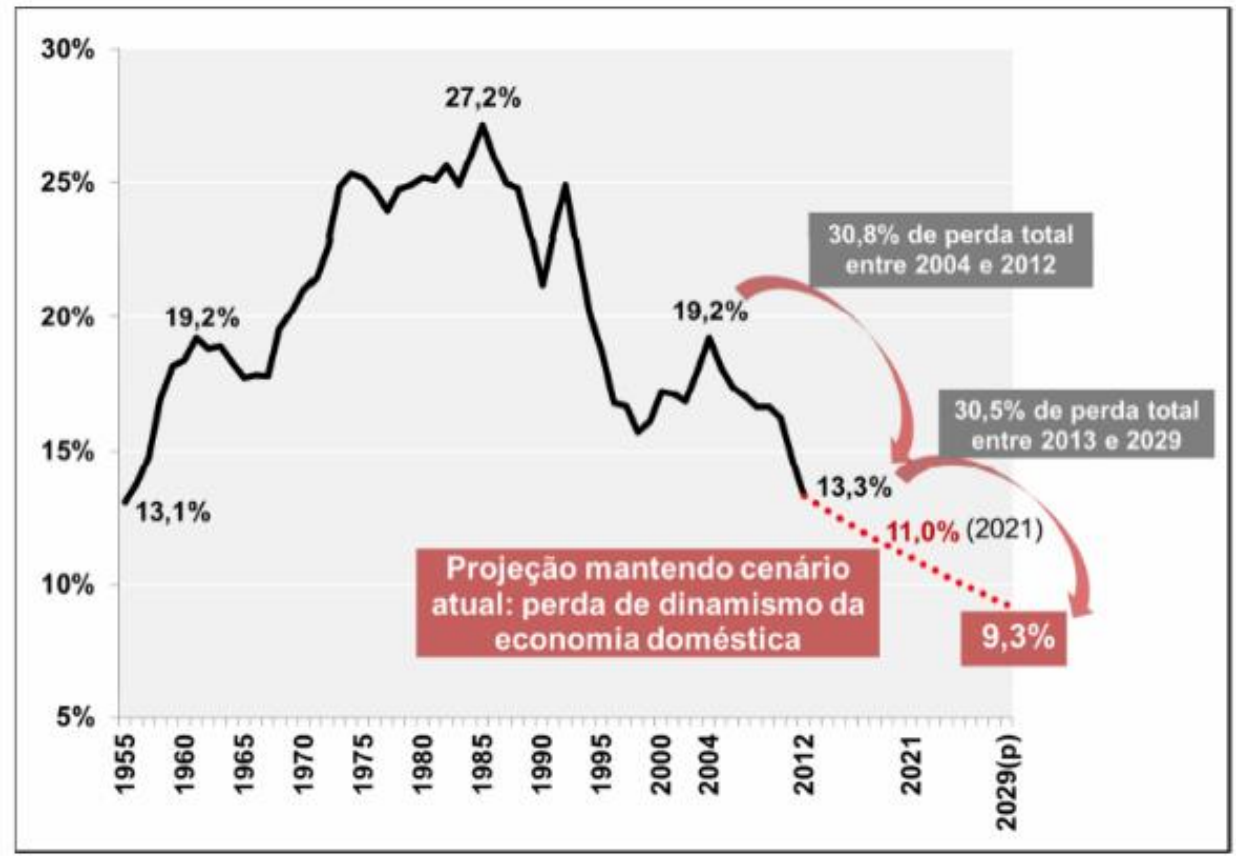

Nota: Série 1955-1994 com ajuste Depecon/FIESP devido à alteraçăo no Sistema de Contas Nacionais. Fonte: SCN/IBGE. Depecon/FIESP. (p) Projeção FEA/USP, Ribeirão Preto.

Figura 1: Porcentagem de contribuição no PIB total do Brasil devido às Indústrias de Transformação

Apesar dos aspectos relacionados com as restrições e a pequena evolução das políticas tributárias de produtos e serviços serem apontados como sendo os principais fatores responsáveis pela baixa taxa de crescimento, estudos indicam que as possíveis causas deste comportamento no Brasil se devem em grande parte pela falta de políticas de incentivo à inovação tecnológica, pela falta de qualificação adequada de profissionais [3] e pela burocracia relacionada com os processos de certificação e regulamentação de empresas nos setores [2].

Assim, a ação de modernização dos processos por parte das empresas nacionais sempre envolve grandes esforços e desafios, pois o acesso à informatização integrada de processos administrativos e de chão de fábrica e a aquisição de maquinário de última geração e componentes específicos para automação industrial são obtidos normalmente através de um processo de importação. Estes aspectos contribuem na elevação dos custos de instalação e manutenção, dificultando ou inviabilizando sua realização.

Por outro lado, embora o Brasil seja considerado um dos países de detentores de grande conhecimento no campo da automação, o mesmo pode ser caracterizado como sendo um utilizador e não um desenvolvedor, existindo poucas empresas 
nacionais que efetivamente produzem tecnologia para automação de processos industriais.

Universidades brasileiras de tecnologia vêm desenvolvendo modernos projetos em automação e robótica alcançando posição de destaque internacionalmente [4]. Porém, estes avanços técnicos desenvolvidos nas Universidades geralmente são fruto de iniciativa própria, com pouco ou nenhum vínculo com segmentos industriais, devido a falta de verbas específicas e políticas de desenvolvimento para o setor [5].

Em uma economia baseada na propriedade e na detenção do conhecimento para poder se tornar competitiva a nação deve ser capaz de gerar e distribuir o conhecimento desenvolvido [6]. Deste modo, é possível estabelecer uma relação direta entre as condições de evolução da automação industrial e o aspecto da competitividade. Como o Brasil não consegue vincular o grande conhecimento gerado em suas Universidades à realidade de sua indústria, existe a vigência de um cenário de baixa participação nas vendas do cenário mundial.

Atualmente, 2014, as exportações brasileiras ainda representam apenas a $1,3 \%$ do comércio mundial, praticamente, mantendo a mesma participação dos últimos 50 anos [2].

A Figura 2 mostra o comparativo dos volumes das participações nas exportações mundiais por parte de países denominados de emergentes na década de 70, ao longo das ultimas quatro décadas, demonstrando que alguns tinham uma participação inferior a do Brasil até a década de 80 , e que hoje, têm capacidade de exportação muito maior que a do Brasil.

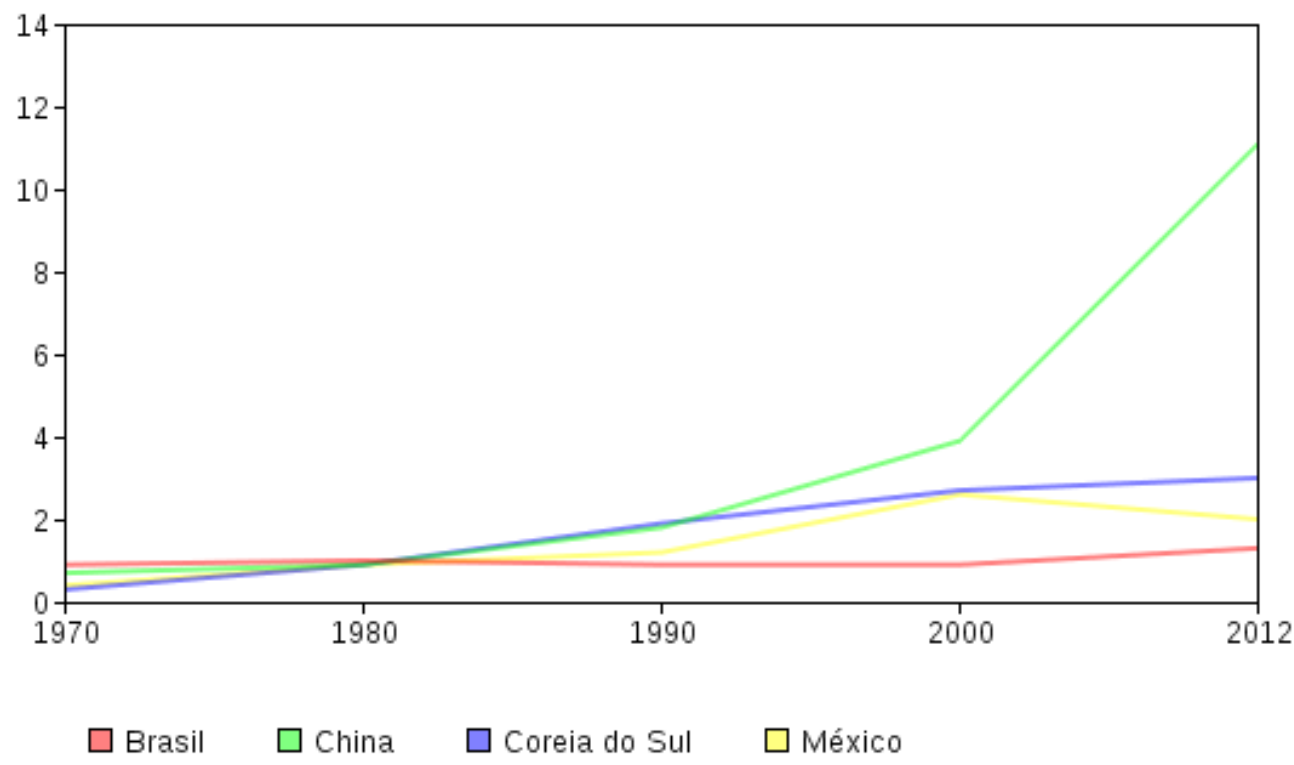

Figura 2: Volume de participação porcentual dos países emergentes (Brasil, China, Coreia do Sul e México) no volume total exportações mundiais nas ultimas décadas.

A comparação da distribuição de robôs industriais polivalentes em vários países pode servir como indicador de desenvolvimento, entretanto contabilizar o montante expresso pelo número total de unidades pode levar a constatações inadequadas devido aos diferentes graus de tamanho e evolução nos setores dos países. Assim, visando à contabilização das diferenças de tamanho nas indústrias que empregam robôs em vários países preferencialmente são utilizadas medidas baseadas na densidade de robôs. Uma dessas medidas de densidade de robôs é o número de robôs industriais polivalentes a cada 10.000 pessoas empregadas na "indústria em geral", que abrange todos os setores.

* Contribuição técnica ao $18^{\circ}$ Seminário de Automação e TI Industrial, 23 a 26 de setembro de 2014, São Paulo, SP, Brasil. 
Em estatísticas publicadas no ano de 2012 pela IFR-International Federation of Robotics [7], a densidade média de robôs no mundo era de aproximadamente 58 robôs por grupo de 10.000 trabalhadores e a densidade de robôs na indústria japonesa era de 306 robôs, enquanto no Brasil esta quantidade era inferior a média mundial (apenas 10 unidades).

Esta densidade de robôs reflete o nível de desenvolvimento tecnológico das empresas do setor industrial relacionado com a robótica industrial no país, onde este é um assunto e uma área de aplicação pouco explorada [8].

A Figura 3 apresenta um panorama resumido sobre a inclusão de robôs na indústria mundial em 2007, através da dimensão do investimento no setor da robótica industrial nos países, evidenciando a falta de investimento nacional nesta tecnologia [9].

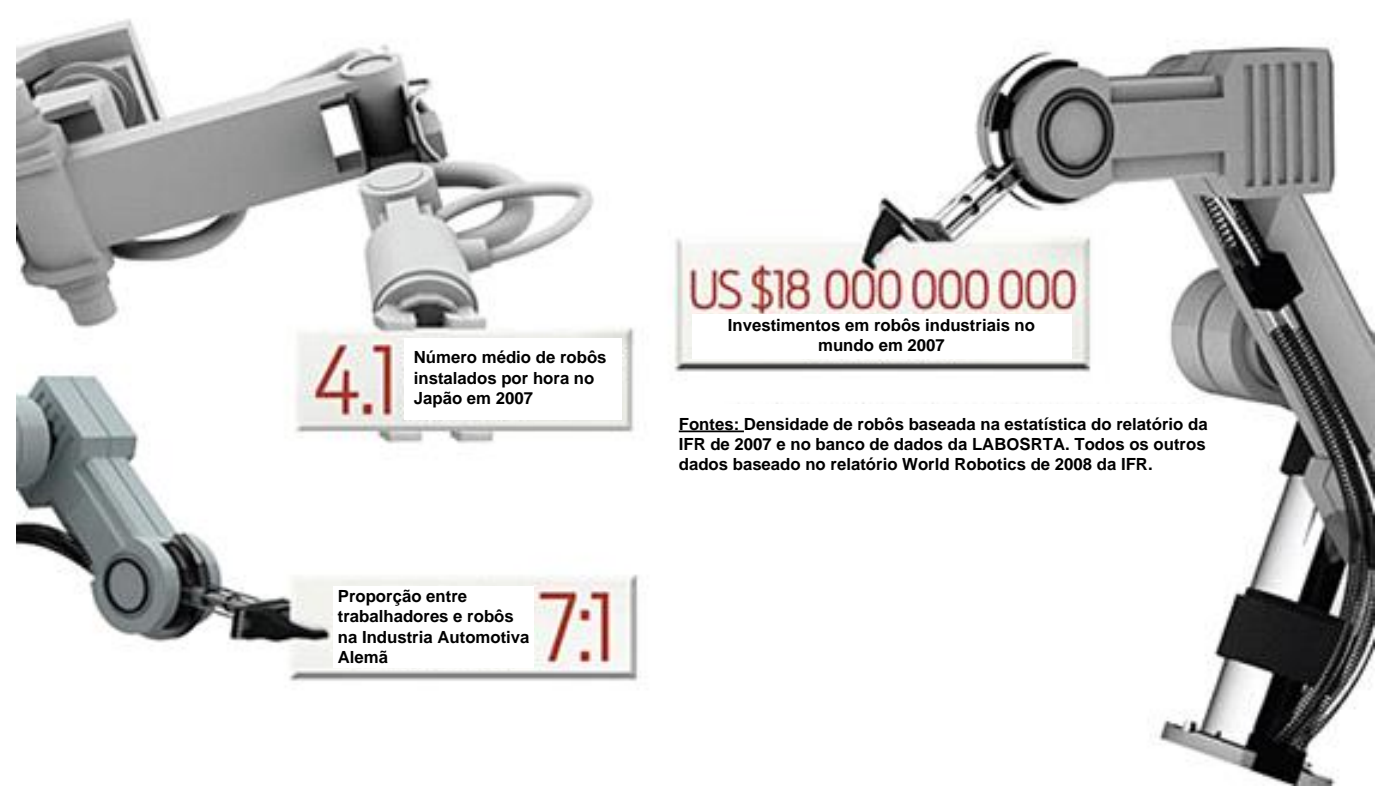

Figura 3: Panorama de investimentos em robótica Industrial em países desenvolvidos.

Basicamente este panorama nacional tem sua causa relacionada com as dificuldades que o empresário nacional encontra para justificar o investimento em uma célula robótica. Os desafios se apresentam nos custos envolvidos com a aquisição do equipamento, com a manutenção e com a reconfiguração das células robóticas.

Devido ao cenário de utilização e não de desenvolvimento, a grande maioria dos robôs comercializados no Brasil são totalmente importados ou apenas montados localmente empregando a maioria dos componentes importados, possuindo assim um nível de nacionalização muito baixo.

Dessa forma, os custos financeiros envolvidos com a implantação de uma célula robótica pode alcançar montantes expressivos, que, devido ao baixo índice de nacionalização, não podem ser custeados por linhas de crédito destinadas ao desenvolvimento industrial nacional, como o Finame do BNDEs [10], significando um obstáculo ao empresário nacional.

Algumas atividades industriais conseguem amortizar melhor estes custos e se desenvolver, como as aplicações que envolvem estações de solda, sendo estas as aplicações que mais empregam robôs no Brasil [4].

A necessidade de adaptações das funcionalidades das células robóticas, reprogramação, também representa outro grande obstáculo para sua aquisição. Com a falta de profissionais capacitados para realizar a tarefa, as empresas

* Contribuição técnica ao $18^{\circ}$ Seminário de Automação e TI Industrial, 23 a 26 de setembro de 2014, São Paulo, SP, Brasil. 
somente adquirem uma célula robótica para uma linha de produção quando têm certeza de que a mesma necessitará sofrer pouquíssimas alterações ao longo dos anos. Em alguns casos pode ocorrer a padronização do formato de um determinado produto para adaptá-lo ao funcionamento da célula [4].

A manutenção representada pela necessidade da reposição de peças é outro grande obstáculo enfrentado pelos empresários no emprego de células robóticas. Geralmente a mecânica destes equipamentos é robusta, precisa e dedicada, além de na maioria das vezes ser importada e feita sob encomenda [6].

Neste sentido, quando há a necessidade de substituição uma peça em um robô por dano, por exemplo, a empresa nacional se depara com os seguintes aspectos:

- o fato de ser frequentemente um equipamento oneroso, importado e feito sob encomenda devido a precisão requerida;

- necessita de mão de obra especializada para a manutenção, muitas vezes estrangeira, apresentando uma relação custo/hora homem alto para os padrões nacionais;

- a manutenção devido aos aspectos anteriores envolve um prazo relativamente alto, que pode deixar o equipamento inoperante por um tempo grande, causando prejuízos.

Apesar de serem conhecidas todas as vantagens do emprego de células robóticas em processos industriais [11-12], tais como, a melhoria na qualidade da atividade devido às invariâncias de desempenho e repetitividade nos processos, além da diminuição dos problemas como absenteísmo devido a falta de ergonomia, licenças médicas ou processos trabalhistas [13-14], devido aos aspectos apresentados anteriormente as células robóticas continuam possuindo aplicações limitadas no Brasil.

Neste sentido, este trabalho apresenta a análise, projeto e o desenvolvimento de um manipulador robótico de baixo custo com adequado potencial para contribuir com a melhoria das condições de utilização de células robóticas no cenário industrial nacional, auxiliando na superação dos desafios existentes na implantação de células robóticas por pequenas e médias empresas.

\subsection{Robôs Manipuladores Industriais}

A norma ISO 8373 define o Robô manipulador industrial como sendo um aparato manipulador polivalente programável em três ou mais eixos, automaticamente controlado, reprogramável, que pode ser fixo no local ou móvel para uso em aplicações industriais de automação [15].

Classificações Por Tipos De Robôs

De acordo com os fabricantes e fornecedores, os robôs industriais podem ser classificados considerando sua estrutura mecânica (e o número dos eixos fornecidos preliminarmente pelo fabricante como configuração inicial). Assim, os principais tipos de robôs industriais podem ser classificados como: lineares (cartesianos e pórtico), cilíndricos, SCARA, articulados e paralelos.

O robô do tipo cartesiano é definido como sendo um robô cujo braço possui três juntas prismáticas e cujos eixos são coincidentes com um sistema de coordenadas cartesiano. Enquanto o robô do tipo cilíndrico é definido como sendo um robô cujos eixos formam um sistema de coordenadas cilíndricas.

Um robô que possui duas juntas rotativas paralelas para fornecer a conformidade em um plano é definido como sendo um robô do tipo SCARA.

* Contribuição técnica ao $18^{\circ}$ Seminário de Automação e TI Industrial, 23 a 26 de setembro de 2014, São Paulo, SP, Brasil. 
O robô do tipo articulado consiste basicamente de um robô cujo braço apresenta pelo menos três juntas rotativas. Enquanto o robô do tipo paralelo pode ser definido com sendo um robô cujos braços têm concorrentes juntas prismáticas ou rotativas.

A Figura 4 ilustra a classificação de robôs industriais conforme sua estrutura mecânica [15].

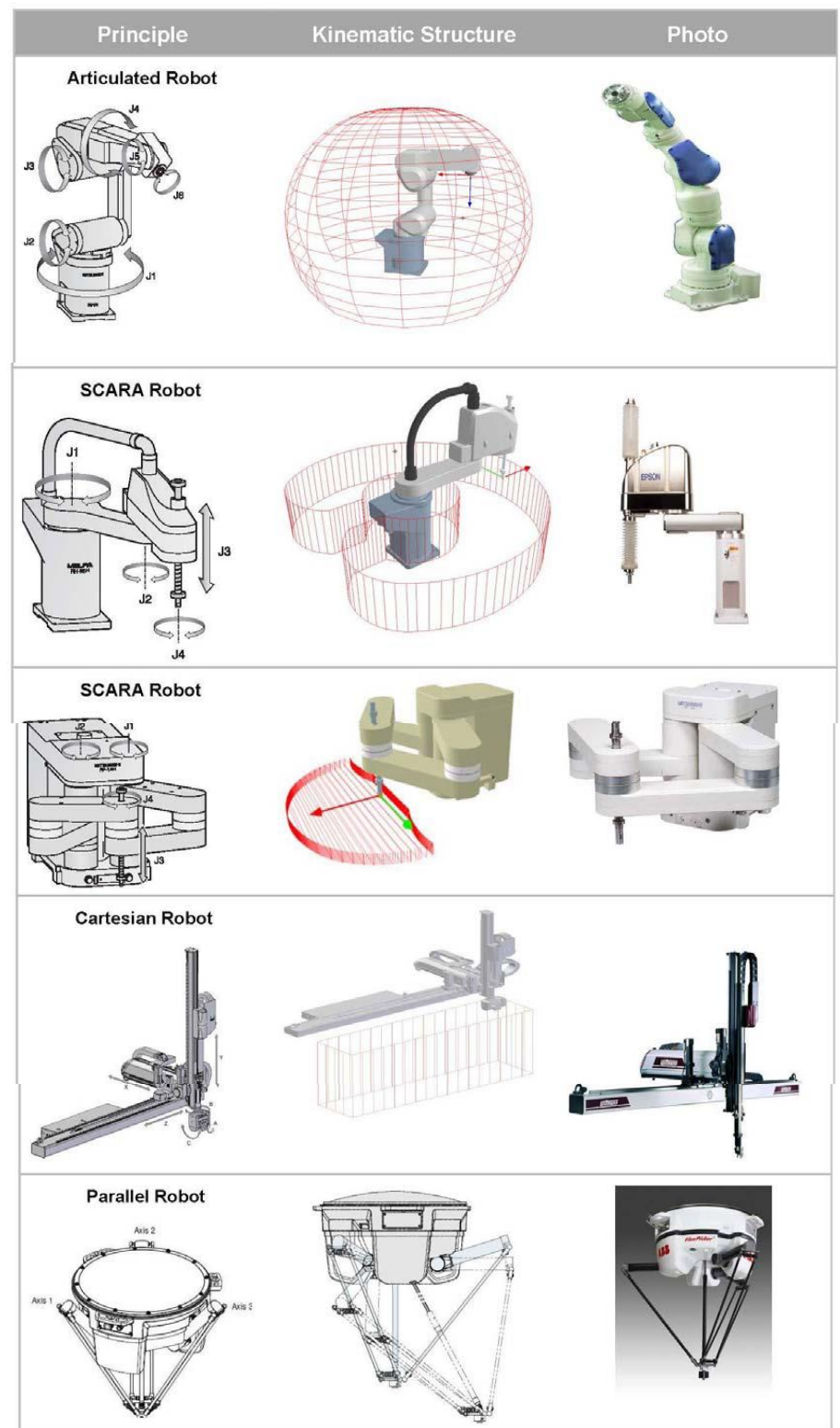

Figura 4 - Classificação de robôs industriais conforme sua estrutura mecânica[15].

\section{PROPOSTA [16-21]}

A proposta deste trabalho consiste no desenvolvimento de um manipulador robótico de baixo custo que atenda os requisitos mínimos de dinâmica para linhas de produção de médias e baixas cadências, onde a aquisição de uma célula robótica convencional de mercado não se justificaria.

Assim, as sete principais características desejadas para um manipulador robótico são apresentadas a seguir:

1) Estrutura leve de baixo custo;

2) Elementos mecânicos de precisão média; 
3) Elementos mecânicos e elétricos não dedicados, facilmente encontrados no mercado;

4) Velocidade semelhante aos dos robôs de mesma arquitetura fornecidos no mercado;

5) Sistema de controle de baixo custo, capaz de compensar a fragilidade da estrutura com recursos de suavização de trajetórias;

6) Software de reconfiguração de manipulação amigável, que exime a empresa da necessidade de se manter um profissional com conhecimentos profundos em automação;

7) Ambiente amigável para operação e manutenção, com recursos de supervisão, histórico de falhas e assistência remota.

Mediante análise da complexidade envolvida nos tipos possíveis de manipuladores robóticos, a arquitetura cartesiana (Figura 5) surgiu como uma opção para emprego no projeto devido a simplicidade envolvida na sua operação e montagem.

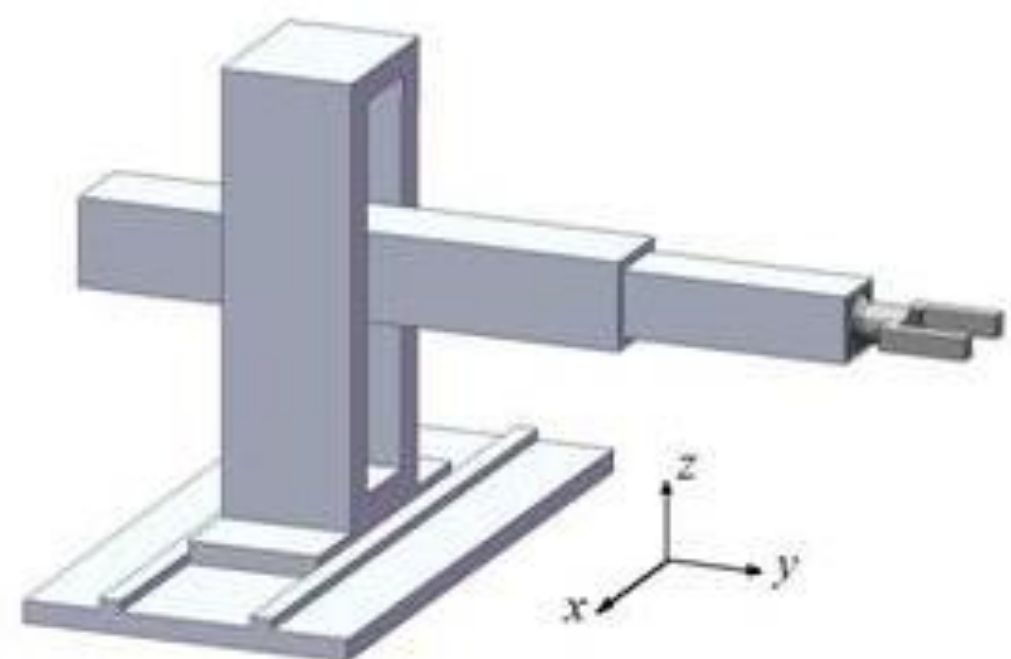

Figura 5: Arquitetura de um Robô Cartesiano.

Os robôs cartesianos trabalham sobe uma filosofia de posicionamento em que cada eixo está a 90 graus do outro, e os motores representam um dos eixos cartesianos $X, Y, Z$. Dessa forma, não se faz necessária a utilização de algoritmos de transformação de coordenadas (cinemáticas inversa/direta).

Este tipo de arquitetura apresenta vantagens e desvantagens em relação aos robôs polares articulados. Entre as vantagens em relação aos robôs polares articulados pode-se citar:

- Precisão dos elementos mecânicos não necessita ser tão alta, pois a transferência de erro é considerada linear;

- Permite a instalação sobre máquinas;

- Apresenta construção considerada simples;

- Apresenta menor consumo para realizar o mesmo movimento, pois existe menor aplicação de torque para verter o efeito da gravidade.

- Apresenta maior alcance por área ocupada;

Entre os aspectos que podem ser considerados como desvantagens, é possível relatar:

- Montagem no local mais complicada por necessidade do nivelamento em um maior perímetro;

- Exige que o ambiente de instalação possua altura elevada (pé direito alto);

* Contribuição técnica ao $18^{\circ}$ Seminário de Automação e TI Industrial, 23 a 26 de setembro de 2014, São Paulo, SP, Brasil. 
- Necessidade dos produtos manipulados sempre ficarem sob a estrutura do robô, o que pode atrapalhar a retirada em algumas aplicações;

Apesar das desvantagens citadas, a estrutura cartesiana ainda é capaz de atender de forma adequada às características de operação destinadas na proposta.

\subsection{Arquitetura do Sistema de Controle em Manipuladores}

Os manipuladores robóticos industriais convencionais presentes no mercado geralmente trabalham com uma arquitetura de controle semelhante à ilustrada na Figura 6. Basicamente a arquitetura apresenta uma interface com o usuário, um controlador de eixos, servodrives e servomotores.
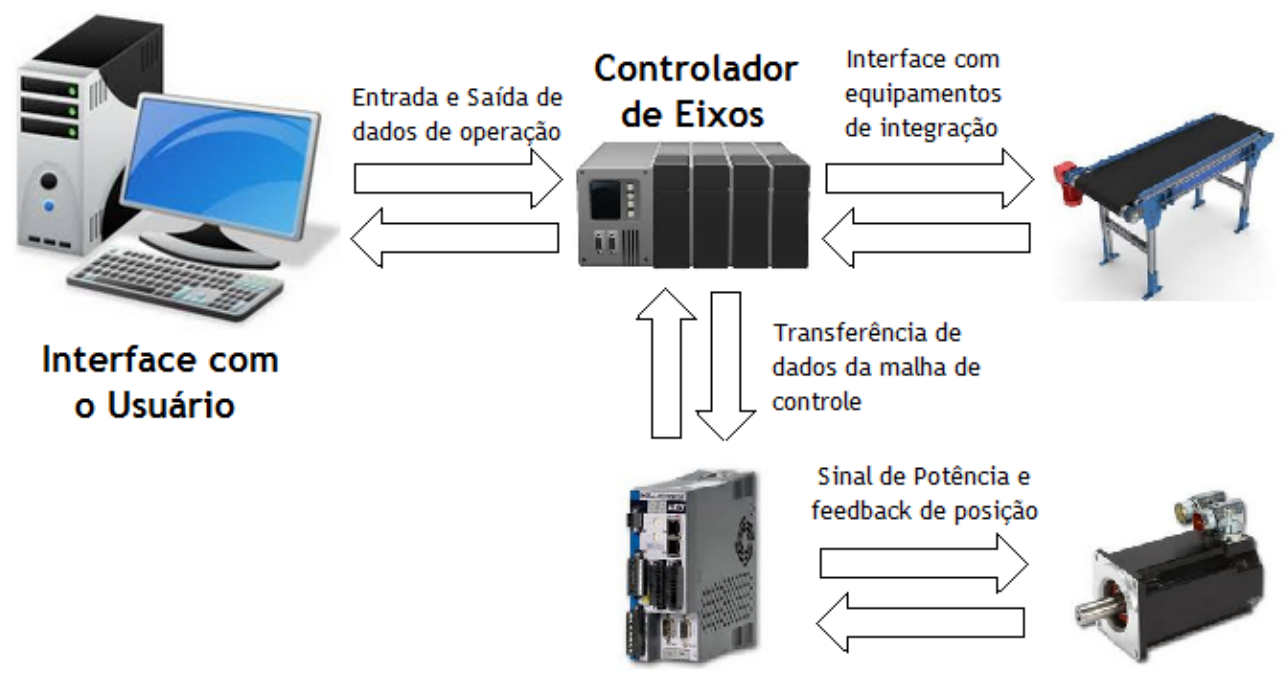

Servodrives

Servomotores

Figura 6: Arquitetura do sistema de controle de manipuladores robóticos industriais.

A Interface de Usuário geralmente utiliza uma plataforma baseada no emprego de um PC industrial funciona como a porta de entrada para os comandos de trabalho da célula robótica. A partir deste elemento, o usuário pode informar os dados das trajetórias desejadas para o Controlador de Eixos, e também, extrair dados de operação do Robô, como posições atuais, produção obtidos através de sensores.

O Controlador de Eixos é o elemento mais importante do sistema, pois é o elemento que integra o sistema de controle e realiza a interface com os dispositivos de integração da célula robótica, como esteiras, garras. Além disso, é responsável pelo gerenciamento dos sinais da malha de controle, enviando dados de posicionamento para o Servodrive, através de protocolos de comunicação ou via sinal analógico, e recebendo a realimentação de posição proveniente do sensor (encoder) acoplado no eixo do Servomotor.

Os Servodrives são os dispositivos responsáveis por acionar os servomotores conforme as condições informadas pelo sistema de controle.

Basicamente, transformam os comandos de posição e velocidade do Controlador de Eixos para sinais de tensão pulsantes através da modulação por largura de pulso (PWM) que são entregues aos Servomotores, que por sua vez, se encarregam de realizar o movimento.

O fluxo convencional de informação desta arquitetura para controle de uma célula robótica é mostrado na Figura 7. 


\section{AUTOMAÇÃO \& TI}
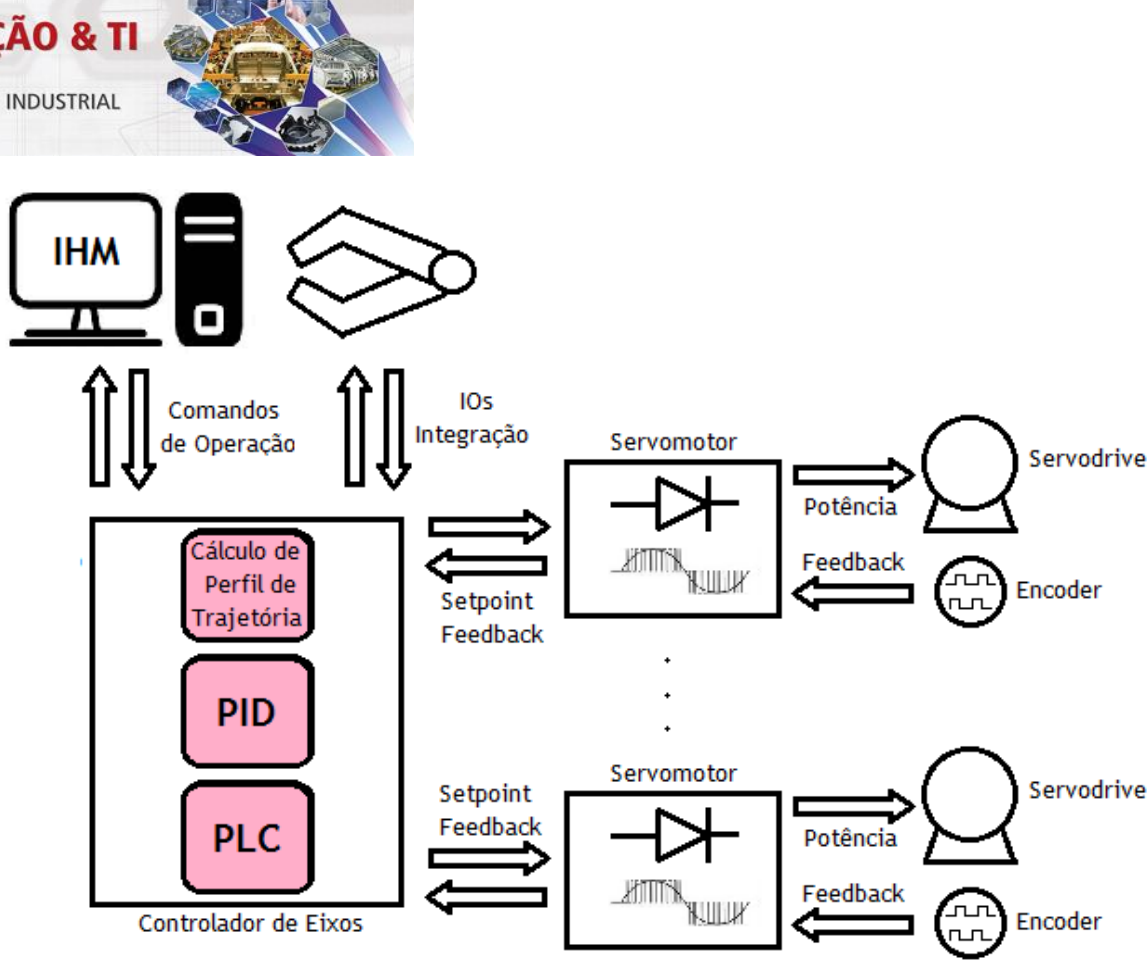

Figura 7: Fluxo de informação de um sistema de controle convencional de um Robô.

Devido a sua característica integradora e controladora, o Controlador de Eixos geralmente representa um elemento de elevado custo no sistema, pois possuem tecnologia totalmente importada.

Uma estratégia para reduzir os custos do protótipo em questão seria conseguir criar um sistema alternativo que fosse capaz de eliminar a necessidade do emprego do Controlador de Eixos no sistema. Assim, no desenvolvimento da proposta adotou-se uma estratégia baseada na utilização do PC responsável pela Interface-HomemMáquina para acomodar um algoritmo que fosse capaz de efetuar os cálculos dos perfis das trajetórias e enviar estas informações de posição/tempo diretamente para Servodrives denominados inteligentes, munidos de malhas de controle integradas, como descrito na Figura 8.

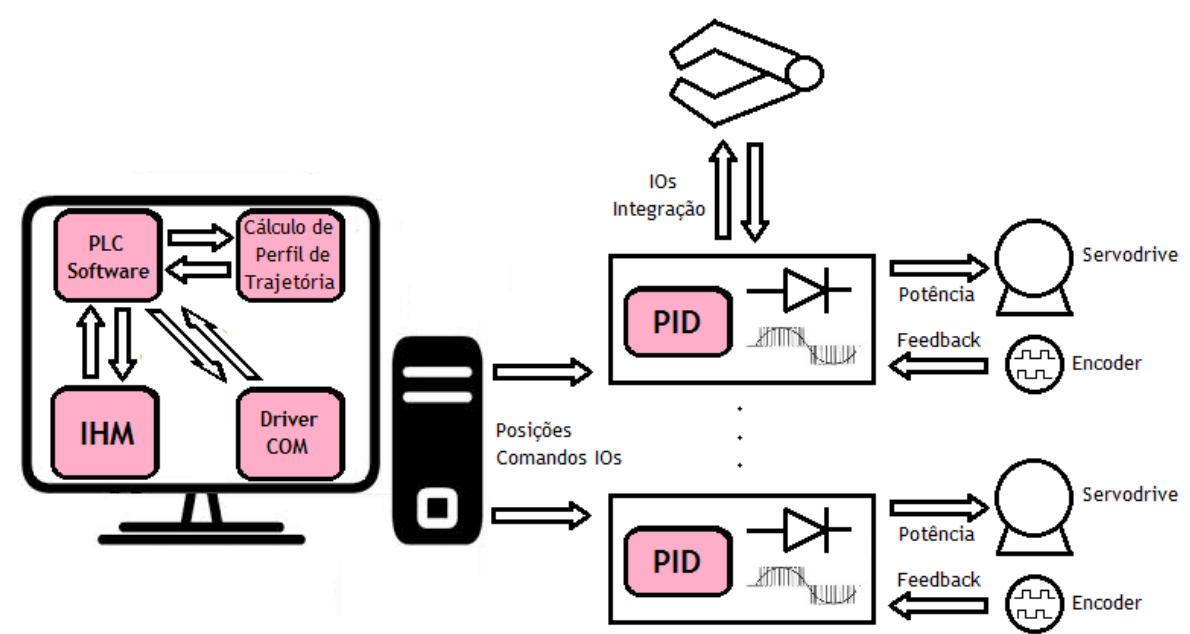

Figura 8: Fluxo de Informação para controle via envio de posições para drives "inteligentes", com malha de controle integrada.

Os Servodrives denominados inteligentes, por possuírem malhas de controle integradas, são largamente utilizados em manipuladores que exigem posicionamento controlado de apenas um eixo. (e nos casos de múltiplos eixos mesmo sendo inteligentes estes requerem a existência de um Controlador de Eixos). Estes apresentam um custo um pouco maior que os denominados servodrives convencionais, sem malhas de controle integradas.

* Contribuição técnica ao $18^{\circ}$ Seminário de Automação e TI Industrial, 23 a 26 de setembro de 2014, São Paulo, SP, Brasil. 
$\mathrm{Na}$ arquitetura proposta os servo-drives inteligentes serão configurados de forma a dispensar o emprego de um controlador de eixos, pois o comando de posicionamento será enviado diretamente aos Servodrives pelo PC através de driver de protocolo de comunicação industrial. Este aspecto operacional possui grande potencial para impactar de forma a diminuir o custo global do sistema de controle.

Os softwares para sequenciamento de operações (PLC) e cálculo de perfis de trajetórias serão desenvolvidos em linguagem de programação. O software PLC estará em comunicação direta com o Driver de Comunicação, para o envio de posições e comandos de Entradas e Saídas Digitais aos Servodrives.

\subsection{Características da Interface com Usuário}

A Interface com o Usuário deverá ser intuitiva e visualmente amigável, tanto para operações de rotina quanto para manutenção e reprogramação de posicionamentos. Estes recursos dispensariam a necessidade de um profissional treinado para a programação e utilização do Robô.

Para atender a estes requisitos, o sistema terá uma base de dados com preferências de trabalho programáveis, assistentes de criação e ajuste de trajetórias e tela de sinótico da célula.

\section{RESULTADOS E DISCUSSÃO}

Um protótipo funcional do manipulador robótico foi construído utilizando tubos em aço soldado para a construção, guias lineares e redutores de média precisão e transmissão por correias sincronizadas, conforme a Figura 9.

O projeto foi desenvolvido de modo que pudesse realizar a manipulação de produtos de até $80 \mathrm{~kg}$ em uma área de aproximadamente 7 metros quadrados.

Para este alcance e capacidade de carga, foram pesquisados preços de vários fornecedores de robôs manipuladores comerciais presentes no mercado. Considerando o custeio do Robô, a mão de obra de instalação e programação, os valores oscilaram entre USD130.000,00 a USD180.000,00.

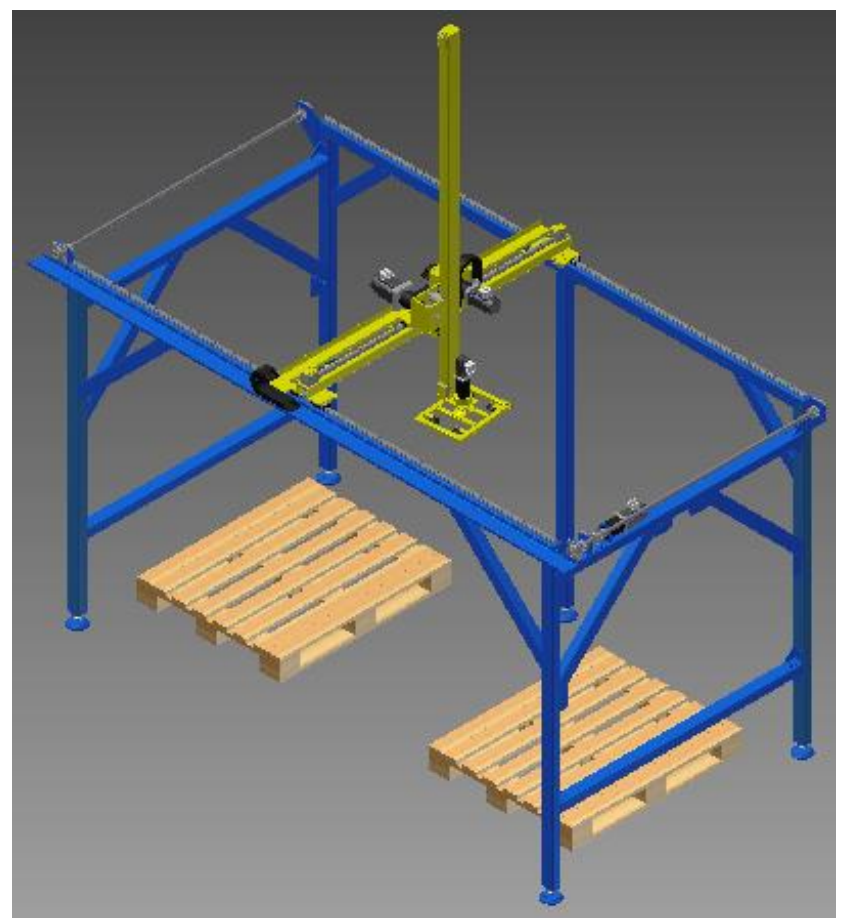

Figura 9: Protótipo de Robô Manipulador Cartesiano.

* Contribuição técnica ao $18^{\circ}$ Seminário de Automação e TI Industrial, 23 a 26 de setembro de 2014, São Paulo, SP, Brasil. 
O preço de venda estimado para projeto proposto foi determinado primariamente considerando a participação dos equipamentos, tributos, mão de obra de usinagem, corte-dobra e programação, o que resultou em um montante aproximado de apenas $42 \%$ do menor custo obtido anteriormente.

As Figuras 10 e 11 apresentam fotos do protótipo do robô manipulador cartesiano implementado.

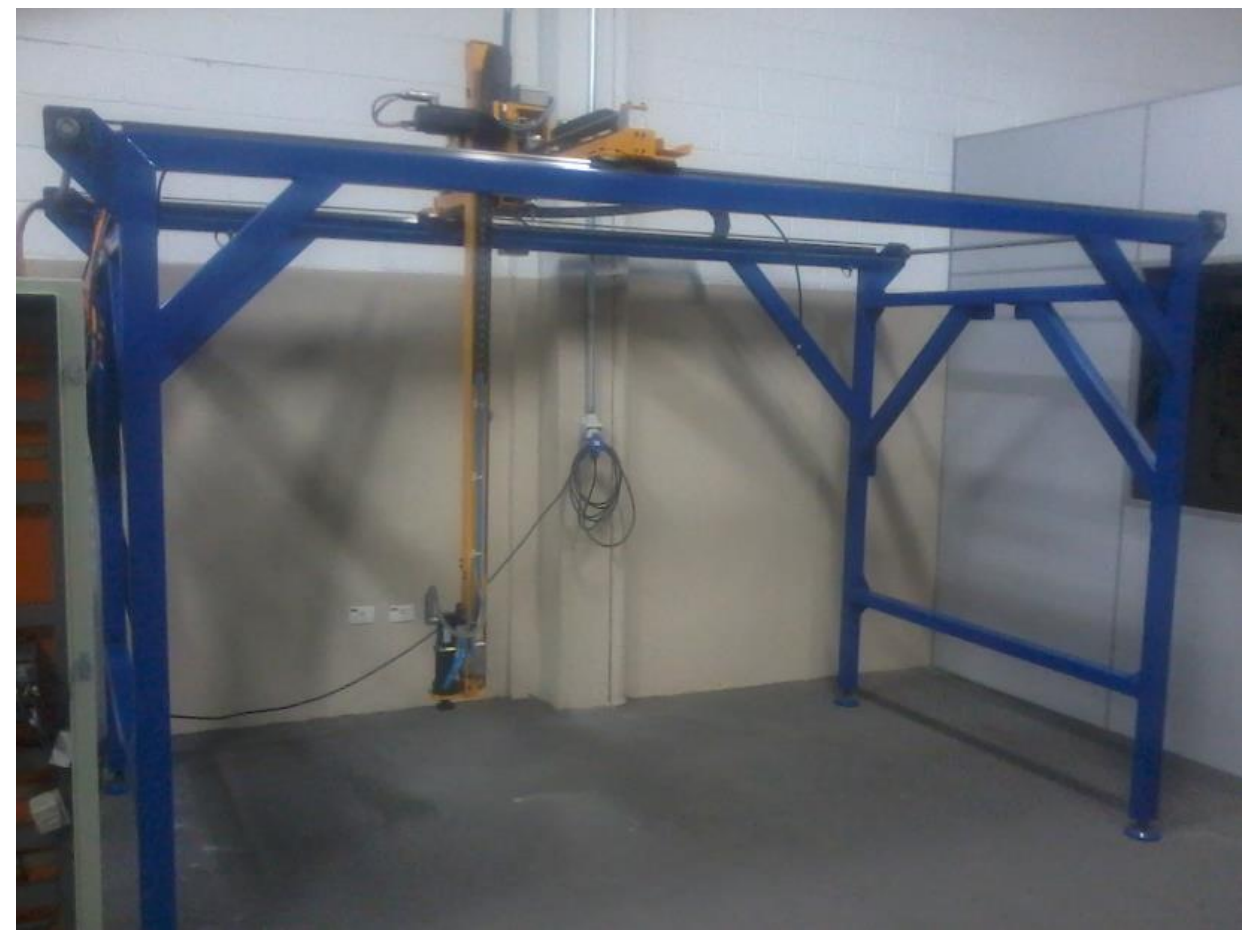

Figura 10: Protótipo Robô Manipulador Cartesiano.

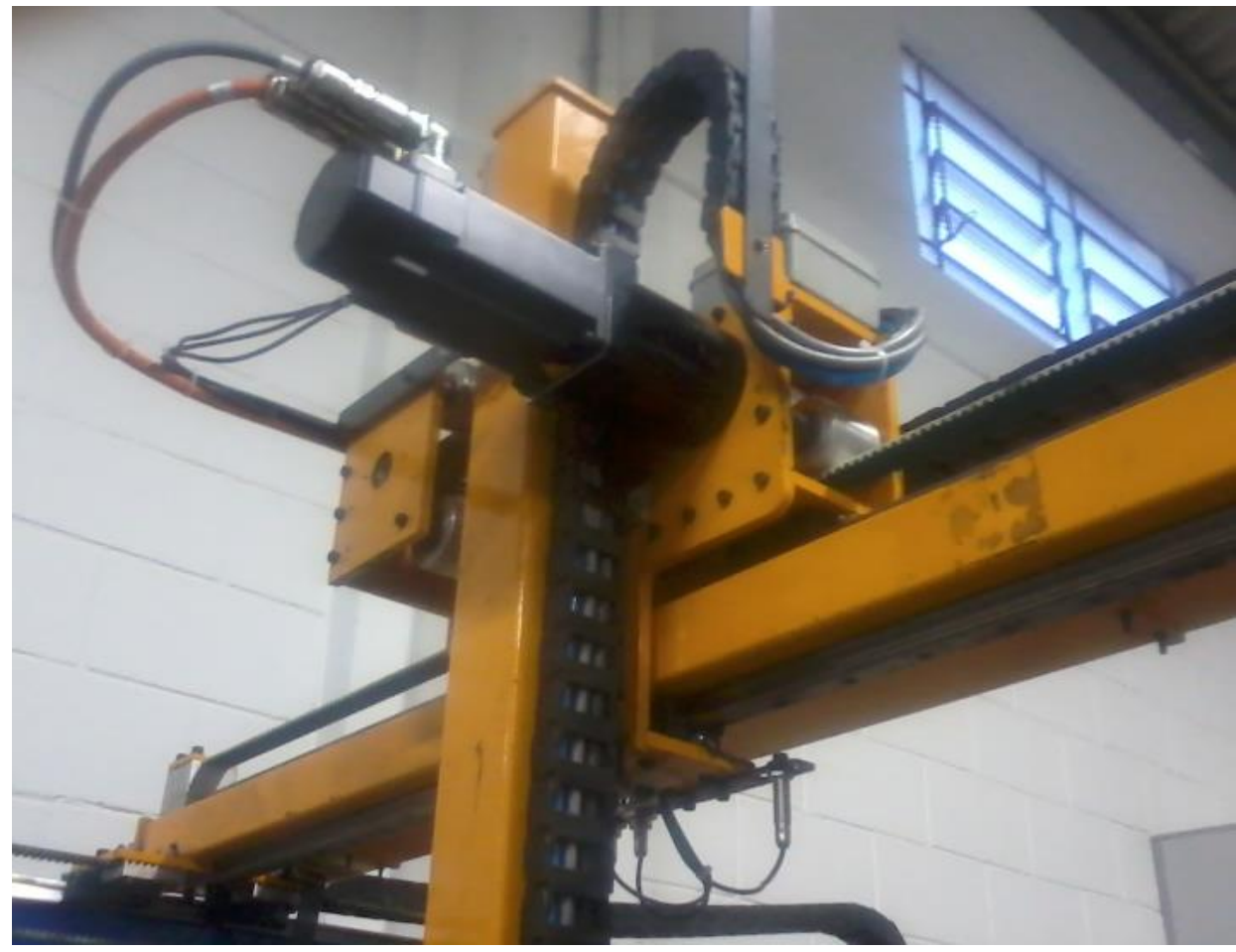

Figura 11: Detalhes dos eixos de movimentação (Y-Z).

Na Figura 12 é possível observar o conceito adotado para o ambiente de operação do manipulador proposto.

* Contribuição técnica ao $18^{\circ}$ Seminário de Automação e TI Industrial, 23 a 26 de setembro de 2014, São Paulo, SP, Brasil. 

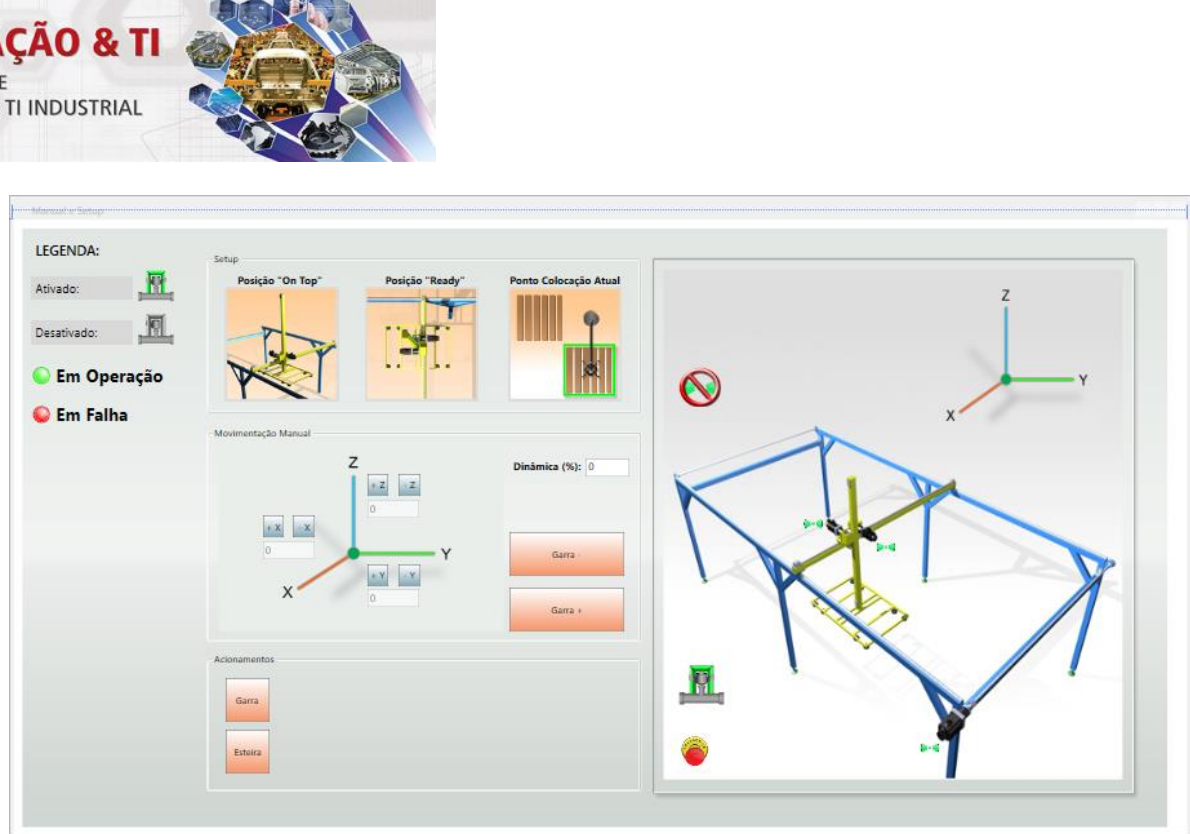

Figura 12: Tela de controle manual do ambiente de operação do Manipulador.

\section{CONCLUSÃo}

Neste trabalho foram avaliadas alternativas para propiciar uma possível redução significativa do custo relacionado com a implantação e a manutenção de um robô manipulador industrial, principalmente em linhas de baixa e média cadência, onde a amortização do investimento em robôs de manipulação existentes no mercado (na grande maioria, importados) usualmente não é alcançada.

O desenvolvimento de um robô do tipo cartesiano, com controle por injeção de posições empregando drives de acionamento denominados "inteligentes", por possuírem circuitos de controle de eixos únicos internos, mostrou ser uma ótima opção para preencher esta lacuna no mercado brasileiro.

A imposição da utilização de componentes de baixo-custo e média precisão para o sistema de transmissão alcançou resultados superiores aos requeridos para 0 processo, ratificados nos testes de movimentação, onde os erros de posicionamento causados pela imprecisão dos componentes quase não foram percebidos, possibilitando um movimento suave e uma entrega precisa do produto ao respectivo destino.

A adaptação de tubos Metalon para construção da estrutura também foi bastante satisfatória. Além de atender os requisitos iniciais de baixo custo e fácil reposição, mostrou-se bastante robusta nas movimentações, com pequenas vibrações que não interferiram na realização do trajeto.

Porém, foi no desenvolvimento do software de controle e da Interface que se obteve o maior ganho:

- A Interface praticamente elimina a necessidade de profissionais treinados para a reprogramação do robô, além de fornecer informações precisas sobre todo o processo de manipulação, facilitando a manutenção dos equipamentos e também o gerenciamento de produção da célula.

- O software de controle, baseado na linguagem C\# .NET, atendeu as exigências de performance, tanto para a realização dos cálculos envolvidos na interpolação dos pontos do trajeto quanto para o envio de posições para os drives, proporcionando uma movimentação suave e precisa.

Portanto, diante do exposto é possível concluir que a solução do manipulador robótico industrial proposto teria grande potencial para fomentar benefícios ao mercado brasileiro, trazendo maior competitividade e qualidade ao processo produtivo de pequenas e médias empresas, situação complexa de se alcançar com as soluções existentes até então.

* Contribuição técnica ao $18^{\circ}$ Seminário de Automação e TI Industrial, 23 a 26 de setembro de 2014, São Paulo, SP, Brasil. 


\section{REFERÊNCIAS}

1 Chiochetta JC, Hatakeyama K, Leite MLG. Evolução histórica da indústria brasileira: desafios, oportunidades e formas de gestão. Congresso Brasileiro de Ensino de Engenharia - COBENGE, setembro 2004.

2 Crespo SG. Indústria no governo Dilma tem pior desempenho desde Collor; UOL Economia, fevereiro 2014;

http://achadoseconomicos.blogosfera.uol.com.br/2014/02/04/industria-no-governodilma-tem-pior-desempenho-desde-collor/; Acesso: março 2014.

3 Bruciapaglia AH, Farines JM, Cury JER. . A Automação no Processo Produtivo: Desafios e Perspectivas. Nexus Ciência e Tecnologia, Florianópolis, 2001; 1(1).

4 Mecatrônica Atual; Mercado de robôs caminha para o 'gargalo; Revista Mecatrônica No9 - abril 2003; http://www.mecatronicaatual.com.br/educacao/1064-mercado-derobs-caminha-para-o-gargalo; Acesso: março 2014.

$5 \quad$ Ayres M. Os robôs no Brasil e no mundo, UOL Tecnologia, outubro 2007; http://tecnologia.uol.com.br/ultnot/2007/10/01/ult4213u146.jhtm; Acesso: março 2014.

6 Salves D. Brasil avança em robótica mas ainda sofre com infraestrutura, UOL Tecnologia, dezembro 2011; http://tecnologia.terra.com.br/robos/brasil-avanca-emrobotica-mas-ainda-sofre-com-

infraestrutura,72f84dbea5bda310VgnCLD200000bbcceb0aRCRD.html; Acesso: março 2014.

7 Relatório: World Robotics 2013 Industrial Robots. Acesso: www.ifr.org/industrialrobots/statistics; Acesso: março 2014.

8 Salim, M.; "Os 10 países mais robotizados do mundo", Revista Exame, janeiro 2012; http://exame.abril.com.br/economia/noticias/os-10-paises-mais-robotizados-do-mundo; Acesso: março 2014.

9 Guizzo E. The Rise of the Machines, IEEE Spectrum, december 2008; http://spectrum.ieee.org/robotics/industrial-robots/the-rise-of-the-machines; Acesso: março 2014.

10 BNDES - Banco Nacional do Desenvolvimento; "BNDES Finame - Financiamento de Máquinas e Equipamentos", Governo Federal Brasileiro;

http://www.bndes.gov.br/SiteBNDES/bndes/bndes_pt/Institucional/Apoio_Financeiro/Pr odutos/FINAME_Maquinas_e_Equipamentos/; Acesso: março 2014.

11 Yoshikawa T. Foundations of Robotics: Analysis and Control. Corona Publishing, 1990.

12 Siciliano B, Villani L, Sciavicco L, Oriolo G. Robotics: Modelling, Planning and Control"; Springer-Verlag London, 2010.

13 Ministério do Trabalho; Manual de aplicação da Norma Regulamentadora no 17 NR17; Secretaria de Inspeção do Trabalho; 2a Edição, 2002.

14 Freire TBF. Aplicação de Robôs nas Indústrias; Universidade Federal do Espírito Santo.

15 World Robotics 2005: Statistics, Market Analysis, Case Studies and Profitability of Robot Investment: http://books.google.com.br/books?id=4B6Ei1 y4WbcC; Acesso: abril 2014.

16 EtherCAT Technology Group: http://www.ethercat.org/; Acesso: abril 2014.

17 CAN in Automation: http://www.can-cia.org/; Acesso: abril 2014.

18 The Modbus Organization: http://www.modbus.org/; Acesso: abril 2014.

19 Memory-Mapped Files: http://msdn.microsoft.com/en-us/library/dd997372.aspx/ : Acesso: abril 2014.

20 cplusplus.com: http://www.cplusplus.com/; Acesso: abril 2014.

21 Code Project : http://www.codeproject.com/Articles/212856/Head-to-head-benchmarkCsharp-vs-NET : Acesso: abril 2014. 